\title{
T-DNA Inheritance Stability of Resveratrol Rice Iksan526 over Multi-generations
}

\author{
Yang Qin ${ }^{1}$, Hong-Il Ahn ${ }^{1}$, Su-Yoen Park', Myung-Ho Lim ${ }^{1}$, Hee-Jong Woo ${ }^{1}$, Kong-Sik Shin ${ }^{1}$, Jin-Hyoung Lee, \\ Hyun-Suk Cho², So-Hyeon Baek, Soon-Ki Park', Soon-Jong Kweon ${ }^{1}$ * \\ ${ }^{1}$ Biosafety Division, National Academy of Agricultural Science, RDA, Jeonju-si, Jeollabuk-do 560-500, Republic of Korea \\ ${ }^{2}$ School of Applied Biosciences, College of Agriculture \& Life Science, Kyungpook National University, Daegu 702-701, Republic \\ of Korea \\ ${ }^{3}$ National Institute of Crop Science, Rural Development Administration, Iksan, Chonbuk, Korea
}

\begin{abstract}
Confirmation of T-DNA inheritance and stability requires testing of several parameters such as phenotypic performance of transgenic lines, transgene integrity structure and expression stability for at least three consecutive generations, and Mendelian inheritance analysis, which are very important to transgenic breeding and commercialization of genetically modified crops (GMOs). In the present study, we measured nine agronomic and yield-related traits of Iksan526 and confirmed stable phenotypic performance comparing to the donor variety Dongjin over three years. Transgene integrity structure, flanking sequence, functional element copy numbers, absence of backbone sequence and transgene expression were all verified in Iksan526 over three consecutive generations, indicating a stable inheritance of the transgene. In addition, phenotypic and genotypic segregation were analyzed on $F_{2}$ and $F_{3}$ populations derived from a cross of Dongjin/Iksan526, and results complied with Mendel's law of segregation based on single transgene locus. This study demonstrated detailed analyses and confirmation of transgene event Iksan526 which is crucial for commercialization of GMO.
\end{abstract}

Keywords Generations, Mendelian inheritance, Resveratrol, Stability, Transgenic

\section{INTRODUCTION}

As one of the most important staple crops, rice is widely consumed for a large part of the world's human population, especially in Asia. In recent years, most efforts had been initiated to improve rice yields, disease resistance, drought or salinity tolerance and nutritional values by genetic engineering in order to meet population growth, economic benefits and health needs (Portrykus 2001; Vasconcelos et al. 2003; Chen et al. 2009; Gu et al. 2013). Baek et al. (2013) developed resveratrol-enriched rice and revealed that its consumption can significantly reduce body weight, blood glucose, triglycerides, total cholesterol and LDLcholesterol. Resveratrol rice breeding shared the same breeding process to the other transgenic crops which started through $R S 3$ gene transformation, evaluation and selection, along with complete molecular characterization. Specifically, analysis of the transgenic line event Iksan526 was initiated for commercialization (Qin et al. 2013).

Submission of biosafety assessment of GM crops is an important requirement for commercialization of GMOs. The general principles for the risk assessment of GM plants and GM-derived food and feeds are described in the EFSA guidance document of the EFSA Scientific Panel on Genetically Modified Organisms and addressed the details of the different components of the risk assessment. One of them is molecular characterization which provides information on the structure and expression of the insert(s) and on the stability of the intended trait(s) (European Food Safety Authority 2011). In addition, transgene inheritance patterns, whether or not follows Mendelian segregation, need to be observed due to a frequency of $10 \%$ non-Mendelian

Received September 2, 2014; Revised September 19, 2014; Accepted September 23, 2014; Published September 30, 2014

*Corresponding author Soon-Jong Kweon, Kwonsj@korea.kr, Tel: +82-63-238-4715, Fax: +82-63-238-4704 
inheritance recorded from transgenic plants produced by Agrobacterium-mediated transformation (Yin et al. 2004). In the previous study, the resveratrol transgenic rice line Iksan526 was identified as one intergenic insertion locus by two copies with inverted repeats conjunction structure and expected mRNA expression and resveratrol production (Qin et al. 2013). However, the complex T-DNA integrity structure of inverted repeats whether it will lead to a instable inheritance from generation to generation not only for the agronomic and yield-related traits, but also T-DNA integrity structure and gene expression, need to be proved. In addition, Mendelian segregation patterns of the hybrid progenies of transgenic line Iksan526 should be analyzed. The results of this study do not only show vital significance to transgene breeding but also as a document to biosafety assessment of the GM rice event Iksan526.

\section{MATERIALS AND METHODS}

\section{Agronomic and yield traits measurement and statistical analysis}

Nine agronomic and yield traits consisting of culm length, panicle length, panicle number, 100-grain weight, weight per plant, unfilled grain number, filled grain number, grain number per panicle and seed set were measured for 100 samples of transgenic line Iksan526 and the donor variety Dongjin from 2011 to 2013 at Suwon GMO experimental field. Mean values, standard deviations and t-test were performed by means of Microsoft Excel.

\section{Resveratrol analysis by HPLC}

A total of $100 \mathrm{mg}$ grain powder from the brown rice of transgenic lines and control Dongjin were obtained every generation for three years. The samples were shakeincubated at $1200 \mathrm{rpm}$ for $30 \mathrm{~min}$ at $30^{\circ} \mathrm{C}$ mixed with 500 ul of $80 \%(\mathrm{v} / \mathrm{v})$ methanol, and centrifuged at $14000 \mathrm{rpm}$ at $4^{\circ} \mathrm{C}$ for $5 \mathrm{~min}$. Then the supernants were filtered by $0.2 \mu \mathrm{m}$ nylon membrane filter for HPLC analysis. Resveratrol standard was obtained from Sigma-Aldrich (\#R5010). The separations were carried out using Waters Symmetry C18 column $(250 \times 4.6 \mathrm{~mm}, 5 \mu \mathrm{m}$ with guard column) and Shimadzu HPLC system (Kyoto, Japan) with PDA detector. The injection volume, flow rate, column temperature and UV detection are $10 \mathrm{ul}, 0.3 \mathrm{ml} / \mathrm{min}, 35^{\circ} \mathrm{C}$ and $308 \mathrm{~nm}$, separately. The mobile phase were A: $0.1 \%$ formic acid in $\mathrm{H}_{2} \mathrm{O}$, and B: $0.1 \%$ formic acid in acetonitrile with programs (20min 70:30, 40min 10:90, 50min 10:90, $52 \mathrm{~min} 90: 10$ and 60min 90:10). Standard calibration with $1.25 \mathrm{ug}, 2.5 \mathrm{ug}, 5 \mathrm{ug}$, and $10 \mathrm{ug}$ showed a linear regression with a correlation $>0.99$.

\section{DNA and RNA sample collection and isolation}

$\mathrm{T}_{6}, \mathrm{~T}_{7}$ and $\mathrm{T}_{8}$ generations of the transgenic resveratrol rice line Iksan526 and its isogenic variety Dongjin were planted at the GMO experimental fields of RDA, Suwon in the rice growing season of 2013. Two lines of isogenic variety 'Dongjin' for every three transgenic lines were established with a spacing pattern of $15 \mathrm{~cm}$ between plants and $30 \mathrm{~cm}$ between rows. Genomic DNAs were isolated from young leaves of rice plants according to the modified cetyltrimethylammonium bromide (CTAB) method (Chen and Ronald 1999).

For gene expression analysis in different growing stages, leaves from $\mathrm{T}_{6}, \mathrm{~T}_{7}$, and $\mathrm{T}_{8}$ generations and the donor variety Dongjin were sampled during seedling stage (June $5^{\text {th }}$ ), tillering (July $12^{\text {th }}$ ), and heading (August $20^{\text {th }}$ ). For gene expression analysis in different organs and tissues, the leaf, stem and spikelet were separately sampled from three generations of transgenic lines and the donor variety Dongjin on August $20^{\text {th }}$, and the seeds were sampled on November $1^{\text {st }}$. Root samples were also collected at seedling stage. All samples for expression analysis were collected with three repeats. The total RNAs were then extracted by using TRIzol reagent (Invitrogen, UK) according to the manufacturer's protocol.

\section{Molecular analysis}

LA-PCR, southern blot hybridization and RT-PCR were performed to detect T-DNA integrity structure, flanking sequence, functional elements, backbone absence and gene expression following the description in Qin et al. 2013. Event-specific primers were designed for LA-PCR and RT-PCR as shown in supplementary Table 1. Specific probes for southern blot hybridization from functional elements and backbone sequence were designed as shown 
in supplementary Table 2 and supplementary Table 3.

\section{Mendelian inheritance analysis}

Phenotypic and genotypic analyses were performed on $F_{2}$ and $F_{3}$ populations in 2013 and 2014. A total of $450 F_{2}$ four-leaf old plants were treated with $0.3 \%$ of herbicide Basta, and the surviving plants were counted after one week. Plants that have survived were transplanted at Suwon GMO experimental field. For $\mathrm{F}_{3}$ generation, 9486 heterozygous lines were used for Basta treatment in 2014 (Supplementary Fig. 4D). For genotypic separation analysis, a total of $300 F_{2}$ and $352 F_{3}$ that have survived from herbicide tolerance screening were PCR using specific primers (Supplemental Fig. 4A and C). The PCR conditions include a predenaturation step at $94^{\circ} \mathrm{C}$ for $5 \mathrm{~min}$, followed by 30 cycles of denaturation at $94{ }^{\circ} \mathrm{C}$ for $30 \mathrm{~s}$, annealing at $55^{\circ} \mathrm{C}$ for $30 \mathrm{~s}$, extension for $1 \mathrm{~min}$ at $72^{\circ} \mathrm{C}$, and final extension for $5 \mathrm{~min}$ at $72^{\circ} \mathrm{C}$.

\section{RESULTS}

\section{Phenotypic traits stability of Iksan526 over generations}

\section{Agronomic and yield traits stability}

Nine agronomic and yield traits were measured over three years. T-test analysis revealed significant difference

Table 1. Comparison and t-test analysis of agronomic and yield traits over three years (generations) of resveratrol transgenic rice Iksan526 and its donor variety Dongjin.

\begin{tabular}{|c|c|c|c|c|c|c|}
\hline Variety & Years & $\begin{array}{l}\text { Culm } \\
\text { length }\end{array}$ & $\begin{array}{l}\text { Panicle } \\
\text { length }\end{array}$ & Panicle number & $\begin{array}{c}\text { Weight/plant } \\
(\mathrm{g})\end{array}$ & $\begin{array}{l}\text { 100-grain weight } \\
(\mathrm{g})\end{array}$ \\
\hline Iksan526 & & $94.15 \pm 4.69$ & $20.74 \pm 1.85$ & $11.17 \pm 2.13$ & $30.63 \pm 7.16$ & $2.73 \pm 0.17$ \\
\hline Dongjin & 2011 & $96.60 \pm 4.27$ & $20.30 \pm 1.57$ & $13.10 \pm 1.85$ & $34.28 \pm 7.93$ & $2.61 \pm 0.10$ \\
\hline$t$ value & & 0.30 & 0.24 & 0.85 & 0.14 & 0.77 \\
\hline Iksan526 & & $83.24 \pm 3.89$ & $22.02 \pm 1.71$ & $8.84 \pm 2.33$ & $26.31 \pm 8.98$ & $2.99 \pm 0.07$ \\
\hline Dongjin & 2012 & $86.32 \pm 2.38$ & $21.26 \pm 1.10$ & $8.89 \pm 2.40$ & $27.53 \pm 8.26$ & $2.83 \pm 0.09$ \\
\hline$t$ value & & 0.83 & 0.47 & 0.02 & 0.14 & $2.15^{\text {z) }}$ \\
\hline Iksan526 & & $81.66 \pm 2.64$ & $20.59 \pm 1.28$ & $7.80 \pm 2.15$ & $15.36 \pm 4.81$ & $2.79 \pm 0.06$ \\
\hline Dongjin & 2013 & $83.89 \pm 2.03$ & $21.30 \pm 0.95$ & $7.80 \pm 2.12$ & $18.85 \pm 5.37$ & $2.74 \pm 0.07$ \\
\hline $\mathrm{t}$ value & & 0.92 & 0.60 & 0.00 & 0.74 & 0.73 \\
\hline Iksan526 & & $85.60 \pm 6.30$ & $21.37 \pm 1.78$ & $8.92 \pm 2.53$ & $23.10 \pm 9.55$ & $2.86 \pm 0.15$ \\
\hline Dongjin & $3 Y$ & $87.78 \pm 5.09$ & $21.08 \pm 1.26$ & $9.11 \pm 2.75$ & $24.57 \pm 8.27$ & $2.76 \pm 0.11$ \\
\hline $\mathrm{t}$ value & & 0.36 & 0.17 & 0.07 & 0.16 & 0.71 \\
\hline Variety & Years & $\begin{array}{c}\text { Unfilled grain } \\
\text { number }\end{array}$ & $\begin{array}{c}\text { Filled grain } \\
\text { number }\end{array}$ & Seed set $(\%)$ & $\begin{array}{c}\text { Grain } \\
\text { number/panicle }\end{array}$ & $\begin{array}{c}\text { Resveratrol } \\
\text { (+ Piceid) (ug/g) }\end{array}$ \\
\hline Iksan526 & & $102.35 \pm 48.88$ & $1121.04 \pm 248.18$ & $91.52 \pm 3.84$ & $101.28 \pm 17.52$ & $4.34 \pm 0.11$ \\
\hline Dongjin & 2011 & $111.10 \pm 45.82$ & $1313.96 \pm 311.99$ & $92.12 \pm 3.18$ & $100.69 \pm 19.07$ & - \\
\hline$t$ value & & 0.01 & 0.01 & 0.18 & 0.00 & - \\
\hline Iksan526 & & $180.46 \pm 81.28$ & $879.91 \pm 298.24$ & $83.03 \pm 4.67$ & $119.16 \pm 17.95$ & $4.27 \pm 0.19$ \\
\hline Dongjin & 2012 & $89.42 \pm 33.71$ & $974.79 \pm 298.06$ & $91.46 \pm 2.80$ & $119.71 \pm 13.49$ & - \\
\hline$t$ value & & 1.20 & 0.32 & 1.90 & 0.03 & - \\
\hline Iksan526 & & $309.57 \pm 94.91$ & $552.23 \pm 176.02$ & $63.75 \pm 5.37$ & $70.64 \pm 10.37$ & $4.48 \pm 0.03$ \\
\hline Dongjin & 2013 & $145.30 \pm 71.19$ & $687.68 \pm 199.60$ & $82.67 \pm 6.20$ & $87.88 \pm 7.23$ & - \\
\hline $\mathrm{t}$ value & & 1.88 & 0.78 & $3.58 * * \mathrm{y})$ & 1.82 & - \\
\hline Iksan526 & & $212.72 \pm 114.19$ & $806.77 \pm 328.59$ & $59.14 \pm 31.03$ & $97.43 \pm 26.64$ & $4.36 \pm 0.11$ \\
\hline Dongjin & $3 \mathrm{Y}$ & $116.98 \pm 58.63$ & $892.45 \pm 304.80$ & $72.31 \pm 33.22$ & $101.94 \pm 18.97$ & - \\
\hline $\mathrm{t}$ value & & 0.90 & 0.26 & 0.42 & 0.18 & - \\
\hline
\end{tabular}


in 100-grain weight $\left(\mathrm{t}=2.45^{*}\right)$ in 2012 and seed set $(\mathrm{t}=$ $3.58^{* *}$ ) in 2013 between Iksan526 lines and the donor variety, Dongjin (Table 1). Analysis of three-year combined agronomic and yield data, however, did not show significant difference between the transgenic lines and Dongjin indicating that Iksan526 lines have stable phenotypic performance and yield production over three generations.

\section{Resveratrol content of transgenic lines}

Resveratrol, as the end product of T-DNA insertion and expression, was detected in the brown rice grains of three generations of transgenic lines by HPLC analysis while it was undetected in Dongjin. The average values of resveratrol content in Iksan526 were $4.34 \pm 0.11 \mathrm{ug} / \mathrm{g}$ in $\mathrm{T}_{6}, 4.27 \pm 0.19$ $\mathrm{ug} / \mathrm{g}$ in $\mathrm{T}_{7}$, and $4.48 \pm 0.03 \mathrm{ug} / \mathrm{g}$ in $\mathrm{T}_{8}$ generations (Supplemental Fig. 1), illustrating relatively stable inheritance and resveratrol production over generations.

\section{Stability of T-DNA integrity structure and gene expression over generations}

\section{Inserted T-DNA integrity and structure stability}

The whole genome sequencing and southern blot hybridization analysis of Iksan526 showed two T-DNAs with head-to-head inverted insertion into the chromosome 12 of Dongjin genome in the previous studies (Qin et al. 2013). To illustrate the inserted T-DNA structure through generations, a long fragment of two T-DNAs (4.4-4.5kb) was amplified by LA-PCR. Four primers consisting of 526GL-F02 and 526GL-C from the first T-DNA side and 526GR-B and 526GR-rv04 from the second T-DNA side of rice genomes at insertion site were designed for Iksan526. Two primers of pubi-rev30 and pubi-rvs13 were designed from 4212 and $4302 \mathrm{bp}$ of transformation vector sequence of inserted T-DNA (upstream of the 13 mer of G residues) as shown in Fig. 1A. By using the four primer sets, LA-PCR was performed for the $1^{\text {st }}$ and the $2^{\text {nd }}$ inserted T-DNA of Iksan 526 through $\mathrm{T}_{6}, \mathrm{~T}_{7}$ and $\mathrm{T}_{8}$ generations (Fig. 1B). The same amplicon size of each primer set (1) (4422 bp) and (2) (4502bp) observed on the left copy of three generations confirmed the $1^{\text {st }}$ T-DNA integrity structure and insertion site implying stable inheritance. Similar result was noted for the $2^{\text {nd }}$ T-DNA (the amplicon size of primer sets (3) was $4412 \mathrm{bp}$ and (4) was 4422 bp). Sequencing analysis of LA-PCR amplicons (2) and (3) verified the same flanking sequences at insertion sites of two $\mathrm{T}$-DNAs over $\mathrm{T}_{6}, \mathrm{~T}_{7}$ and $\mathrm{T}_{8}$ generations (Supplemental Fig. 2).

\section{T-DNA functional elements insertion stability}

The enzyme restriction site for each functional elements, and the expected band numbers and sizes for inserted two DNAs of Iksan526 were shown in Fig. 2A. 100 pg positive control derived from the gel elutions from ScaI digested T-DNA vector (from left border to the upstream

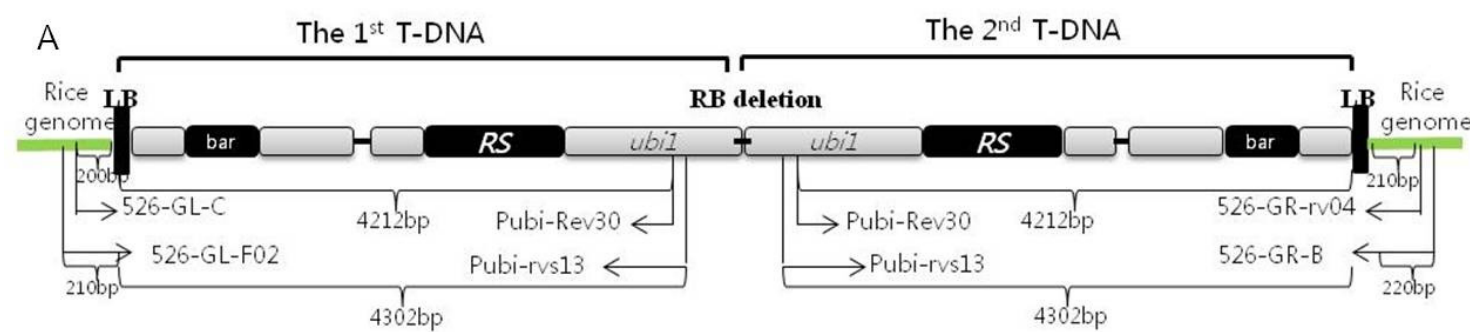

B

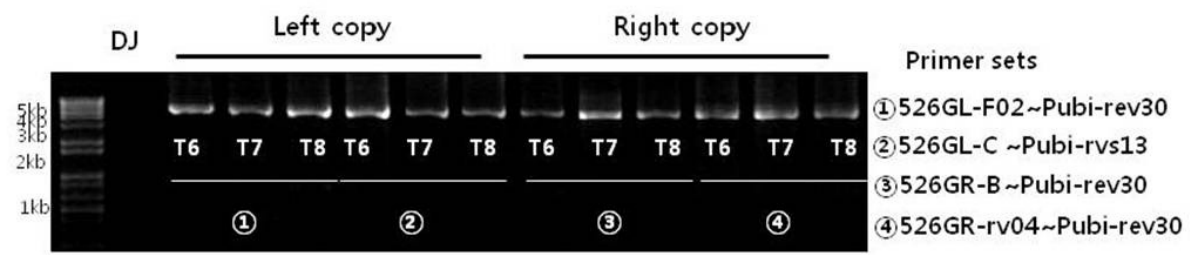

Fig. 1. Confirmation of T-DNA integrity structure and generational stability of Iksan526. A. The basic molecular information of inserted T-DNA and primer design for LA-PCR; B. T-DNA flanking sequence analysis through three generations by LA-PCR. 
about $299 \mathrm{bp}$ of ubiquitin promoter) with a length of $5.04 \mathrm{~kb}$ was obtained. The observed band numbers and sizes from southern blot hybridizations were depicted in Fig. 2B. As expected, two bands were observed for each membrane hybridization: $2 \mathrm{~kb} / 8 \mathrm{~kb}$ for $b a r, 3.5 \mathrm{~kb} / 4.5 \mathrm{~kb}$ for Nos terminator, $3.5 \mathrm{~kb} / 5 \mathrm{~kb}$ for $35 \mathrm{~S}$ promoter, and $6 \mathrm{~kb} / 10 \mathrm{~kb}$ for $35 \mathrm{~S}$ terminator. Each band was observed on the membrane after hybridization with ubiquitin promoter and $R S$ gene. These results are attributed to the two copies T-DNA insertion with inverted headto-head structure which is consistent with the expected results. In comparison, there is no signal detected on the negative control Dongjin and the $5.04 \mathrm{~kb}$ band on the positive control.

\section{Stability of backbone exclusion}

Two kinds of enzymes, ClaI and BamHI, were used to digest the DNAs of three generations of Iksan526 (Supplemental Fig. 3A). If backbone sequences were indeed inserted into rice genomes, two bands should be detected on the membrane after the hybridization of ClaI digested DNAs with backbone specific probes which overlapped at $6.226 \mathrm{~kb}$ backbone sequence. Moreover, one band should be detected on membrane after hybridization of BamHI digested DNAs with corresponding specific backbone probes. However, none of the bands produced indicates the backbone in rice genome sequence of Iksan526 as shown in Supplemental Fig. 3C. The same performances of three generations suggested that genome of Iksan526 did not carry the backbone sequence, while it stably passed on the transgene over three generations.

\section{Stability of foreign gene expression}

The inserted T-DNA is composed of two expression cassettes of Ubi: $R S$ and 35S:bar. Expressions of $R S$ and bar genes were determined by reverse-transcript PCR as shown in Fig. 3. Stability of expressions of these genes were verified regardless of growing stages such as seedling, tillering and heading, or generations $\left(T_{6}, T_{7}\right.$ and $\left.T_{8}\right)$.

\section{Mendelian inheritance analysis for transgene}

Phenotypic and genotypic screening were carried out on

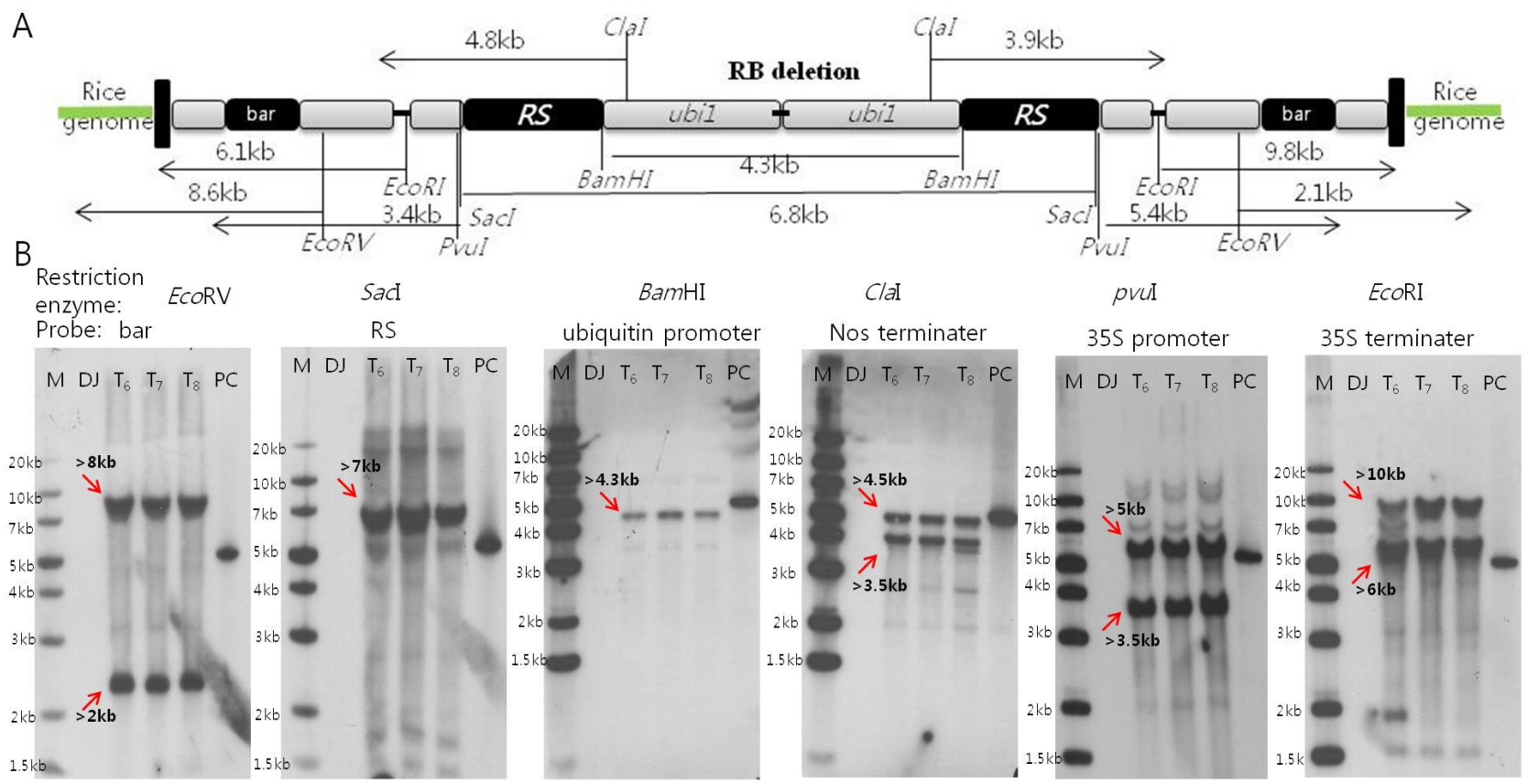

Fig. 2. Confirmation on copy numbers of six functional elements for Iksan526 using Southern blot hybridization. A. The restriction enzyme sites of inserted T-DNA and their expected band sizes; B. Copy numbers of six functional elements through three generations. * M: Generuler $1 \mathrm{~kb}$ plus ladder; NC: Dongjin (negative control); $\mathrm{T}_{6 \sim 8}$ : generation of Iksan526; PC: Positive control (psb2220-5.04kb) 
two consecutive populations $\mathrm{F}_{2}$ and $\mathrm{F}_{3}$ derived from a cross between Dongjin and Iksan526 $\left(\mathrm{T}_{6}\right)$, to confirm one locus T-DNA insertion in accordance with Mendel's law of segregation in hybrid progeny population. A phenotypic segregation ratio of 3:1 was observed in $\mathrm{F}_{2}$ population after treatment with Basta where 321 plants survived and 129 died, and in $\mathrm{F}_{3}$ population where 7100 plants survived and 2386 died (Table 2). PCR assay revealed 92 homologous and 208 heterozygous in $F_{2}$ population and 120 homologous and 232 heterozygous in $F_{3}$ population (Supplemental Fig. 4B and E) which fit the 1:2 segregation ratio. Results of genetic analysis of $\mathrm{F}_{2}$ and $\mathrm{F}_{3}$ populations indicated that the phenotypic and genotypic segregation ratios of transgene were consistent to Mendel's law of segregation on single gene locus.

\section{DISCUSSION}

Whether or not a transgenic trait has a predicted inheritance and expression pattern over multi-generations, conformation to Mendelian segregation is crucial to transgene breeding and GMOs commercialization (Zhong 2001). In addition, GMOs with inverted repeated structure

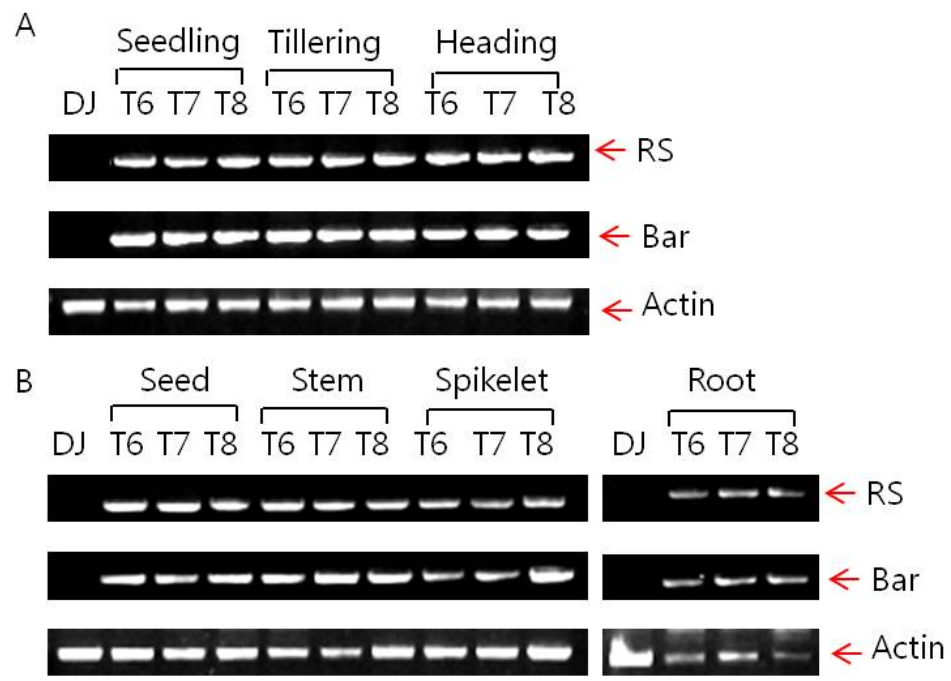

Fig. 3. Inserted resveratrol synthase gene and bar gene expression of Iksan526 by RT-PCR. A. Gene expression in different growing stage; B. Gene expression in different tissues.

Table 2. Phenotypic and genotypic separation ratio at $F_{2}$ and $F_{3}$ populations from a cross Dongjin/lksan526.

\begin{tabular}{|c|c|c|c|c|c|c|}
\hline Population & $\begin{array}{l}\text { Phenotype/ } \\
\text { genotype }\end{array}$ & Treatment & $\begin{array}{l}\text { Expected } \\
\text { separation } \\
\text { ratio }\end{array}$ & \multicolumn{2}{|c|}{ Observed separation ratio } & Possibility \\
\hline \multirow{2}{*}{$\begin{array}{l}\text { Dongjin/ } \\
\text { Iksan526 } \mathrm{F}_{2} \\
\text { population }\end{array}$} & $\begin{array}{l}\text { Phenotypic } \\
\text { separation }\end{array}$ & Basta & $3: 1$ & $\begin{array}{c}\text { Resistant } \\
321\end{array}$ & $\begin{array}{c}\text { Susceptible } \\
129\end{array}$ & $>0.90$ \\
\hline & $\begin{array}{l}\text { Genotypic } \\
\text { separation }\end{array}$ & PCR & $1: 2$ & $\begin{array}{c}\text { Homologous } \\
92 \\
\end{array}$ & $\begin{array}{l}\text { Heterozygous } \\
208^{\mathrm{z})}\end{array}$ & $>0.90$ \\
\hline \multirow{2}{*}{$\begin{array}{l}\text { Dongjin/ } \\
\text { Iksan526 F } \\
\text { population }\end{array}$} & $\begin{array}{l}\text { Phenotypic } \\
\text { separation }\end{array}$ & Basta & $3: 1$ & $\begin{array}{c}\text { Resistant } \\
7100\end{array}$ & $\begin{array}{c}\text { Susceptible } \\
2386\end{array}$ & $>0.90$ \\
\hline & $\begin{array}{l}\text { Genotypic } \\
\text { separation }\end{array}$ & PCR & $1: 2$ & $\begin{array}{c}\text { Homologous } \\
120\end{array}$ & $\begin{array}{c}\text { Heterozygous } \\
232\end{array}$ & $>0.90$ \\
\hline
\end{tabular}

\footnotetext{
${ }^{z)}$ the survival heterozygous lines of $F_{2}$ population were used for genetic analysis of $F_{3}$ population.
} 
transgenes usually show the instability of DNA integrity leading to transgene inactivation or silencing during the development from generation to generation (Muskens et al. 2000; Lechtenberg et al. 2003). Thus, based on the prerequisite of a characterization of two head-to-head copies of one locus by intergenic insertion and high gene expression in the previous study (Qin et al. 2013), the confirmation and document of phenotypic performance, integrity structure, functional expression for at least three generations (years), and Mendelian inheritance patterns through two hybrid progeny population is the main goal in the present study.

In summary, agronomic and yield-related traits of Iksan526 were evaluated and compared to those of Dongjin for three years and stable phenotypic performance was confirmed. Moreover, stability of integrity structure stability and expression were verified through analyses of flanking sequence, inserted T-DNA sequence, functional element copy numbers and size, backbone absence confirmation, mRNA expression, and end product of resveratrol content over three successive generations. A similar research was carried out on PAC rice (Oh et al. 2012), but our study presented more detailed information especially on the complex T-DNA integrity structure of the event Iksan526.

Transgenes may not always follow Mendelian segregation in some cases due to endogenous locus disruption and interference with the endogenous biochemical pathways by biochemical product (Pawlowski and somers 1996; Hood et al. 1997; Yin et al. 2004), however, such is not the case in Iksan526. Mendelian inheritance analysis revealed that transgenes of Iksan526 followed Mendelian segregation. Taken together, the event Iksan526 is stably inherited and thus fits into biosafety assessment of GMOs.

\section{ACKNOWLEDGMENTS}

This work was supported by grant PJ009528 from the Biogreen 21 R\&D Program, Rural Development Administration, Republic of Korea.

\section{REFERENCES}

Baek SH, Shin WC, Ryu HS, Lee DW, Moon EJ, Seo CS, Hwang E, Lee HS, Ahn MH, Jeon YJ, Kang HJ, Lee SW, Kim SY, DSouza R, Kim HJ, Hong ST, Jeon JS. 2013. Creation of resveratrol-enriched rice for the treatment of metabolic syndrome and related diseases. PLoS One. 8 , e57930

Chen H, Lin YJ, Zhang QF. 2009. Review and prospect of transgenic rice research. Chinese Sci. Bull. 54: 4049-4068.

Chen DH, Ronald PC. 1999. A rapid DNA minipreparation method suitable for AFLP and other PCR applications. Plant Mol. Biol. Rep. 17: 53-57.

European Food Safety Authority (EFSA). 2011. EFSA Panel on Genetically Modified Organisms (GMO). Science Opinion on Guidance for risk assessment of food and feed from genetically modified plants. EFSA J. 9: 2150.

Gu JF, Qiu M, Yang JC. 2013. Enhanced tolerance to drought in transgenic rice plants overexpressing $\mathrm{C} 4$ photosynthesis enzymes. Crop J. 1: 105-114.

Hood E, Witcher D, Maddock S, Meyer T, Baszczynski C, Bailey M, Flynn P, Register J, Marshall L, Bond D, Kulisek E, Kusnadi A, Evangelista R, Nikolov Z, WoogeC, Mehigh R, Herman R, Kappel W, Ritland D, Li CP, Howard J. 1997. Commercial production of avidin from transgenic maize: characterization of transformant, production, processing, extracting and purification. Mol. Breed. 3: 291-306.

Lechtenberg B, Schubert D, Forsbach A, Gils M, Scjmidt R. 2003. Neither inverted repeat T-DNA configurations nor arrangements of tandemly repeated transgenes are sufficient to trigger transgene silencing. Plant J. 34: 507-517.

Muskens MWM, Vissers APA, Mol JNM, Kooter JM. 2000. Role of inverted DNA repeats in transcriptional and post-transcriptional gene silencing. Plant Mol. Biol. 43: 243-260.

Oh SD, Park SY, Sohn SI, Kim JK, Park JS, Park SK, Cho HS, Ahn BO, Lee KJ. 2012. Evaluation and Assessment of Biosafety Carotenoid-biofortified Rice (PAC): Progeny Stability Study for Four Generations. Korean J. Breed. Sci. 44: 579-587.

Pawlowski WP, Somers DA. 1996. Transgene inheritance in plants genetically engineered by microprojectile bombardment. Mol. Biotechnol. 6: 17-30. 
Potrykus I. 2001. Gold rice and beyond. Plant Physiol. 125: 1157-1161.

Qin Y, Ahn HI, Kweon SJ, Baek SH, Shin KS, Woo HJ, Cho HS, Lee JH, Lim MH. 2013. Molecular characterization of transgenic rice producing resveratrol. Plant Breed. Biotech. 1: 406-415.

Vasconcelos M, Datta K, Oliva N, Khalekuzzaman M,
Torrizo L, Krishnan S, Oliveira M, Goto F, Datta SK. 2003. Enhanced iron and zinc accumulation in transgenic rice with the ferritin gene. Plant Sci. 164: 371-378.

Yin ZM, Plader W, Malepszy S. 2004. Transgene inheritance in plants. J. Appl. Genet. 45: 127-144.

Zhong GY. 2001. Genetic issues and pitfalls in transgenic plant breeding. Euphytica 118: 137-144. 
Supplemental Table 1. The primer sequence information of LA-PCR.

\begin{tabular}{|c|c|c|}
\hline Primers & Primer sequence & Primer location \\
\hline \multicolumn{3}{|c|}{ Primers of flanking regions from rice genomes } \\
\hline 526GL-F02 & CAATTCGGTCTCATTAGCCTACCTCA & 210bp from $1^{\text {st }}$ T-DNA on chr. 12 \\
\hline $526 \mathrm{GL}-\mathrm{C}$ & GTGCTTGTTGTCTTCTCTTACG & $200 \mathrm{bp}$ from $1^{\text {st }}$ T-DNA on chr. 12 \\
\hline 526GR-B & GATATAGACCTAGCACAGAAAGG & $220 \mathrm{bp}$ from $2^{\text {nd }}$ T-DNA on chr. 12 \\
\hline 526GR-rv04 & CAGAAAGGACACATGTCCCGTTGAGAGA & $210 \mathrm{bp}$ from $2^{\text {nd }}$ T-DNA on chr. 12 \\
\hline \multicolumn{3}{|c|}{ Common primer from plasmid vector (pSB2220) } \\
\hline Pubi-rvs 13 & ССССССТСТСТАССТТСТСТАGАТС & $4302 \mathrm{bp}$ from left border \\
\hline Pubi-rev30 & TTAGATCCGTGCTGCTAGCGTTC & $4212 \mathrm{bp}$ from left border \\
\hline
\end{tabular}

Supplemental Table 2. The primer sequence information of specific probes from six functional elements and inner control actin for RT-PCR.

\begin{tabular}{|c|c|c|c|c|}
\hline Functional elements & Primer names & Primer sequences & Expected size & Specific enzymes \\
\hline \multirow{2}{*}{$35 \mathrm{~S}$ terminater } & $35 s-t e r-f$ & ATTCGGGGGATCTGGATTTTAGTACT & \multirow{2}{*}{$187 \mathrm{bp}$} & \multirow{2}{*}{ EcoRI } \\
\hline & $35 s-t e r-r$ & CGAGTTTCTCCATAATAATGTGTGAG & & \\
\hline \multirow{2}{*}{$35 \mathrm{~S}$ promoter } & 35 s-pro-f & GGTAGACTCGAGAGAGATAGATTTG & \multirow{2}{*}{$152 \mathrm{bp}$} & \multirow{2}{*}{ PvuI } \\
\hline & 35 s-pro-r & TGATGTGATATCTCCACTGACGTA & & \\
\hline \multirow{2}{*}{ Nos-terminater } & Nos-ter-f & GCGATAATTTATCCTAGTTTGCGCGCTA & \multirow{2}{*}{$244 \mathrm{bp}$} & \multirow{2}{*}{ ClaI } \\
\hline & Nos-ter-r & CGGAGCTCGAATTTCCCCGATCGTTC & & \\
\hline \multirow{2}{*}{ Ubiquitin promoter } & ubi-pro-f & GTCCTGTTGTCAAAATACTCAATTGTC & \multirow{2}{*}{$276 \mathrm{bp}$} & \multirow{2}{*}{ BamHI } \\
\hline & ubi-pro-r & AGTGCCAAGCTTGCATGCCTGCAGTGC & & \\
\hline \multirow{2}{*}{ Bar } & bar-for & GAAGTCCAGCTGCCAGAAAC & \multirow{2}{*}{$400 \mathrm{bp}$} & \multirow{2}{*}{ EcoRV } \\
\hline & bar-rev & AAGCACGGTCAACTTCCGTA & & \\
\hline \multirow{2}{*}{$\begin{array}{l}\text { Resveratrol } \\
\text { synthase }\end{array}$} & Rs-for & GCATTGTTTGCGGATGGAGCTG & \multirow{2}{*}{$500 \mathrm{bp}$} & \multirow{2}{*}{ SacI } \\
\hline & Rs-rev & TTATATGGCCACACTGCG & & \\
\hline \multirow{2}{*}{ Actin } & fw & CTGCTATGTACGTCGCCATC & \multirow{2}{*}{$440 \mathrm{bp}$} & \multirow{2}{*}{-} \\
\hline & rv & GTCTCATGGATACCCGCAG & & \\
\hline
\end{tabular}

Supplemental Table 3. The primer sets for confirmation on absence of T-DNA vector backbone sequence in transgenic rice line Iksan526.

\begin{tabular}{|c|c|c|c|}
\hline Backbone & Primer name & Primer sequence & Expected size \\
\hline \multirow{2}{*}{ Pair1 } & rsbcbn-1-fw & GATACAGGCAGCCCATCAGTC & \multirow{2}{*}{$753 \mathrm{bp}$} \\
\hline & rsbcbn-1-rv & TTTCAAGGGCTTTGTTCATCTTCA & \\
\hline \multirow{2}{*}{ pair2 } & rsbcbn-2-fw & CACTTTGAACGGCATGATGG & \multirow{2}{*}{$797 \mathrm{bp}$} \\
\hline & rsbcbn-2-rv & CAGTATTTGTATCTGCGCTCTG & \\
\hline \multirow{2}{*}{ pair3 } & rsbcbn-3-fw & GCGGTGGTTTGTTTGCCGGATCAAGAGC & \multirow{2}{*}{$809 \mathrm{bp}$} \\
\hline & rsbcbn-3-rv & GATTGTACTGAGAGTGCACCATA & \\
\hline \multirow{2}{*}{ pair4 } & rsbcbn-4-fw & GCGAGTCAGTGAGCGAGGAAGC & \multirow{2}{*}{$944 b p$} \\
\hline & rsbcbn-4-rv & GTGGCAGCGCCGGAGAGTTC & \\
\hline \multirow{2}{*}{ pair5 } & rsbcbn-5-fw & CCGCCTCCTCCTTCAAATCGTA & \multirow{2}{*}{ 794bp } \\
\hline & rsbcbn-5-rv & CGCCCAAGGGCGACGAGCAA & \\
\hline \multirow{2}{*}{ pair6 } & rsbcbn-6-fw & CATGATGCTGCGACTATCG & \multirow{2}{*}{$781 \mathrm{bp}$} \\
\hline & rsbcbn-6-rv & AACCGTTCTTGAATCAGAACC & \\
\hline \multirow{2}{*}{ pair7 } & rsbcbn-7-fw & TAACTCAAATGAGTTTTGATTTG & \multirow{2}{*}{$769 \mathrm{bp}$} \\
\hline & rsbcbn-7-rv & GCCAAGCTGGCGGCCTGG & \\
\hline \multirow{2}{*}{ pair8 } & rsbcbn-8-fw & CATCACCTTTTTAGACGG & \multirow{2}{*}{$771 \mathrm{bp}$} \\
\hline & rsbcbn-8-rv & GCACCAGGCGCGACCGC & \\
\hline \multirow{2}{*}{ pair9 } & rsbcbn-9-fw & CACTGTCACAACGTCGCCAG & \multirow{2}{*}{$562 \mathrm{bp}$} \\
\hline & rsbcbn-9-rv & GGTTTATCCGTTCGTCCA & \\
\hline
\end{tabular}



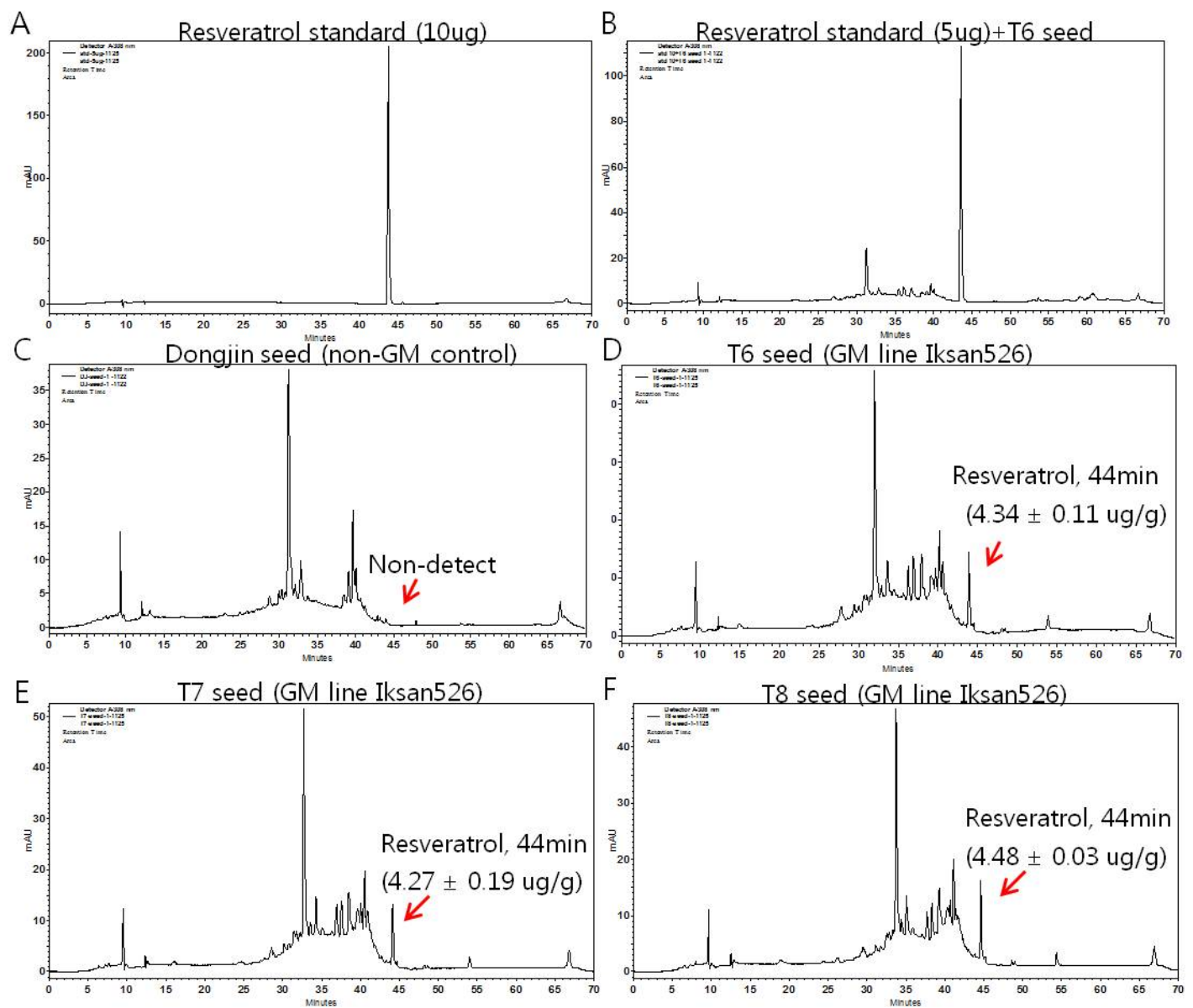

Supplemental Fig. 1. Resveratrol contents analysis for the brown rice grains of three generations for transgenic rice line Iksan526 and their non-detect control Dongjin. A. Resveratrol standard of 10ug; B. A mixture of 5 ug resveratrol standard and the resveratrol extracts from $\mathrm{T}_{6}$ seed of Iksan526; C. The donor variety Dongjin as a non-detect negative control; D, E and $\mathrm{F}$ indicated the resveratrol detection from $\mathrm{T}_{6}$, $\mathrm{T}_{7}$ and $\mathrm{T}_{8}$ brown rice grains of Iksan526, respectively.

The $1^{\text {st }}$ T-DNA

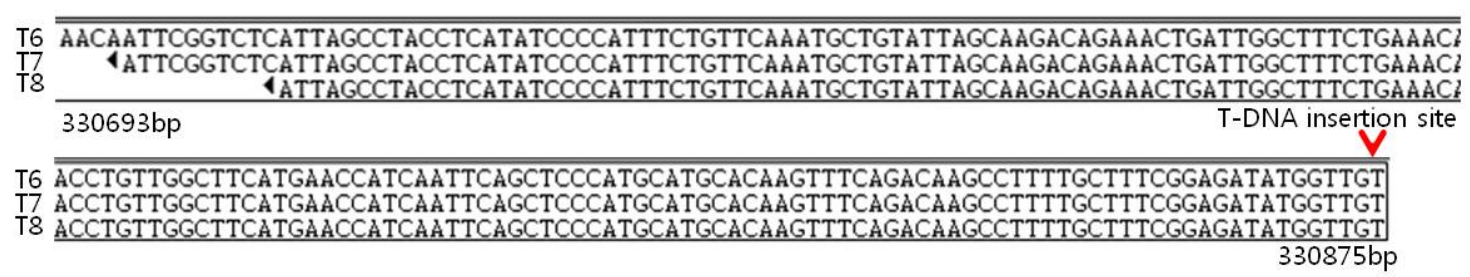

The $2^{\text {nd }}$ T-DNA

T6 i GTGTAGAGACTTAGGATCTAGTAGGTGAGATCAGGACTTCTAATATCATTAGCTCTCCTGCTACTTAATTGAGTTTGGGGTGGTTTGAGG

T7 I|GTGTAGAGACTTAGGATCTAGTAGGTGAGATCAGGACTTCTAATATCATTAGCTCTCCTGCTACTTAATTGAGTTTGGGGTGGTTTGAGG

T8 IT-GAGACTTAGGATCTAGTAGGTGAGATCAGGACTTCTAATATCATTAGCTCTCCTGCTACTTAATTGAGTTTGGGGTGGTTTGAGG $331073 \mathrm{bp}$ T-DNA insertion site

T6 GCTTAATTAGTTCGTGTACATACTATCTGGATCCTACTGTACTAGAGACCATGTGAAGACAAATTAATTGT

T7 GCTTAATTAGTTCGTGTACATACTATCTGGATCCTACTGTACTAGAGACCATGTGAAGACAAATTAATTGT

'GCTTAATTAGTTCGTGTACATACTATCTGGATCCTACTGTACTAGAGACCATGTGAAGACAAATTAATTGT $330903 \mathrm{bp}$

Supplemental Fig. 2. Flanking sequence of T-DNA insertion over three generations by LA-PCR. 
A

B

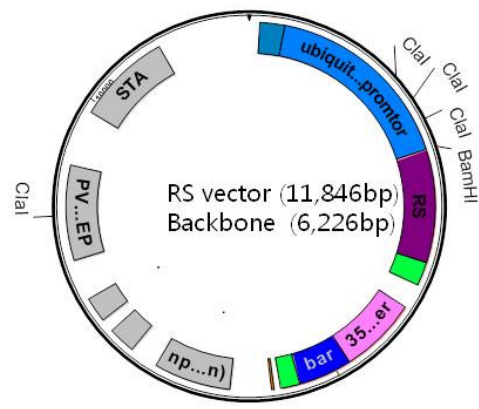

\begin{tabular}{|c|c|c|c|c|}
\hline \multirow{2}{*}{$\begin{array}{l}\text { Backbone } \\
\text { Enzyme }\end{array}$} & \multicolumn{2}{|c|}{ Expected results (band number) } & \multirow{2}{*}{$\begin{array}{l}\text { Observed results } \\
\text { (band number) }\end{array}$} & \multirow{2}{*}{$\begin{array}{l}\text { Postive contro } \\
\text { (size/bp) }\end{array}$} \\
\hline & Backbone presence & Backbone absence & & \\
\hline & 1 & 0 & 0 & $5.04 b p$ \\
\hline Clal & 2 & 0 & 0 & $5.04 b p$ \\
\hline
\end{tabular}

C

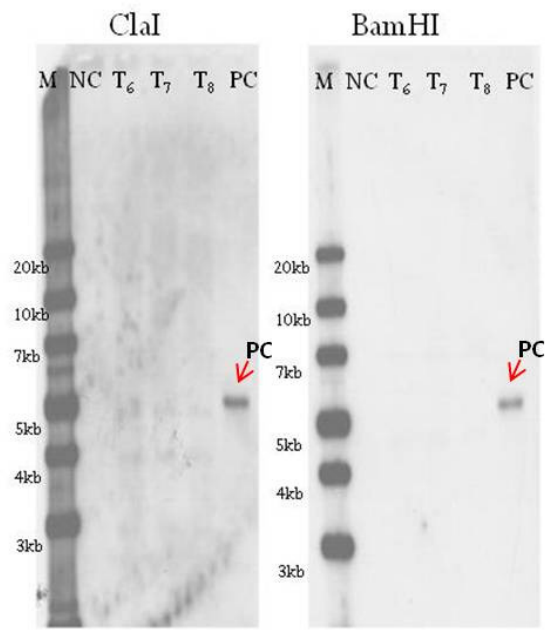

Supplemental Fig. 3. Backbone sequence absence confirmation for three generations of Iksan526; A. The restriction enzyme sites of plasmid construction vector; B. The expected and observed band numbers by two enzymes after hybridization; C. Confirmation on absence of plasmid vector backbone sequence of three generations of transgenic rice line Iksan526 by using southern blot hybridization. ${ }^{*} \mathrm{M}$ : Generuler $1 \mathrm{~kb}$ plus ladder; NC: Dongjin (negative control); $\mathrm{T}_{6-8}$ : generation of Iksan526; PC: Positive control (psb2220-5.04kb).
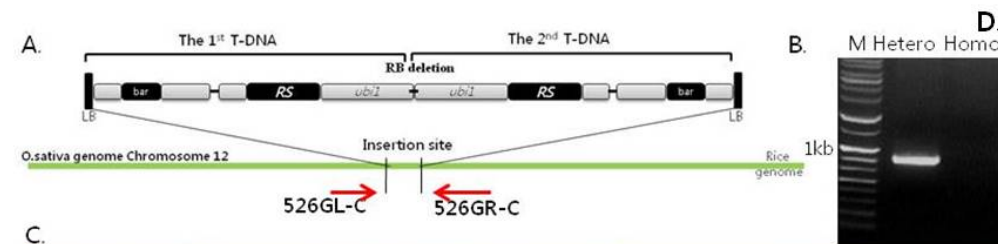

\begin{tabular}{|l|c|c|}
\hline Primer name & \multicolumn{1}{|c|}{ Primer sequence } & \multicolumn{1}{c|}{ Primer location } \\
\hline 526GL-C & GTGCTTGTTGTCTTCTCTTACG & From LB 210bp of genomic DNA \\
\hline 526GR-C & TGCAGAAATTAATGTGGGTGG & From RB 630bp of genomic DNA \\
\hline
\end{tabular}

$$
\text { E. }
$$

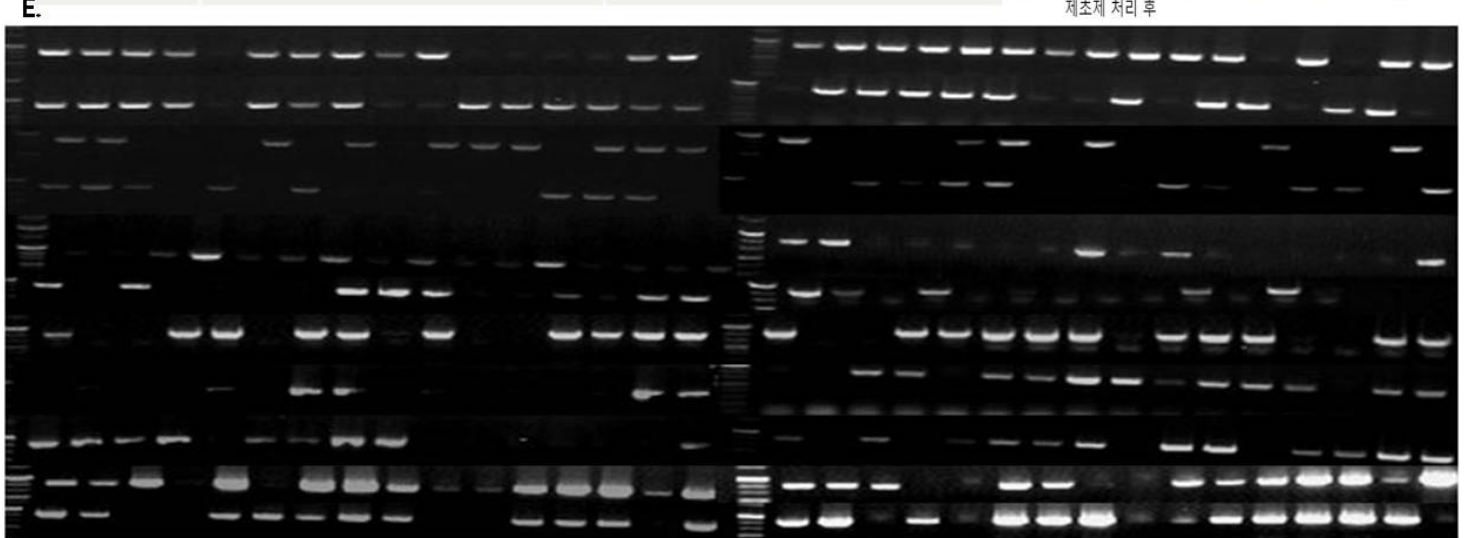

Supplemental Fig. 4. Phenotypic and genotypic separation analysis for $F_{3}$ population derived from a cross of Dongjin/ Iksan526 $\left(\mathrm{T}_{6}\right)$. A. A strategy of primer design for genotypic separation analysis; B. PCR amplification to differentiate heterozygous and homozygous genotypes; C. Specific primer sequence and location on rice chromosome; D. 4-leaf old plants before and after basta treatment; E. Genotypic separation of $352 \mathrm{~F}_{3}$ population. 